\title{
High production of triterpenoids in Yarrowia lipolytica through manipulation of lipid components
}

\author{
Jin-Lai Zhang ${ }^{1,2 \dagger}$, Qiu-Yan Bai ${ }^{1,2+}$, Yang-Zi Peng ${ }^{1,2}$, Jie Fan ${ }^{1,2}$, Cong-Cong Jin ${ }^{1,2}$, Ying-Xiu Cao ${ }^{1,2^{*}}$ \\ and Ying-Jin Yuan ${ }^{1,2}$
}

\begin{abstract}
Background: Lupeol exhibits novel physiological and pharmacological activities, such as anticancer and immunityenhancing activities. However, cytotoxicity remains a challenge for triterpenoid overproduction in microbial cell factories. As lipophilic and relatively small molecular compounds, triterpenes are generally secreted into the extracellular space. The effect of increasing triterpene efflux on the synthesis capacity remains unknown.

Results: In this study, we developed a strategy to enhance triterpene efflux through manipulation of lipid components in Y. lipolytica by overexpressing the enzyme $\triangle 9$-fatty acid desaturase (OLE1) and disturbing phosphatidic acid phosphatase (PAH1) and diacylglycerol kinase (DGK1). By this strategy combined with two-phase fermentation, the highest lupeol production reported to date was achieved, where the titer in the organic phase reached $381.67 \mathrm{mg} / \mathrm{L}$ and the total production was $411.72 \mathrm{mg} / \mathrm{L}$ in shake flasks, exhibiting a 33.20-fold improvement over the initial strain. Lipid manipulation led to a twofold increase in the unsaturated fatty acid (UFA) content, up to 61-73\%, and an exceptionally elongated cell morphology, which might have been caused by enhanced membrane phospholipid biosynthesis flux. Both phenotypes accelerated the export of toxic products to the extracellular space and ultimately stimulated the capacity for triterpenoid synthesis, which was proven by the 5.11 -fold higher ratio of extra/intracellular lupeol concentrations, 2.79-fold higher biomass accumulation and 2.56-fold higher lupeol productivity per unit OD in the modified strains. This strategy was also highly efficient for the biosynthesis of other triterpenes and sesquiterpenes, including a-amyrin, $\beta$-amyrin, longifolene, longipinene and longicyclene.
\end{abstract}

Conclusions: In conclusion, we successfully created a high-yield lupeol-producing strain via lipid manipulation. We demonstrated that the enhancement of lupeol efflux and synthesis capacity was induced by the increased UFA content and elongated cell morphology. Our study provides a novel strategy to promote the biosynthesis of valuable but toxic products in microbial cell factories.

Keywords: Triterpenoids, Lipid manipulation, Unsaturated fatty acids, Cell morphology, Yarrowia lipolytica

\footnotetext{
*Correspondence: caoyingxiu@tju.edu.cn

${ }^{\dagger}$ Jin-Lai Zhang and Qiu-Yan Bai contributed equally to this work

${ }^{2}$ Collaborative Innovation Center of Chemical Science and Engineering (Tianjin), Tianjin University, Tianjin 300072, China

Full list of author information is available at the end of the article
}

\begin{abstract}
Background
Triterpenoids are a class of antineoplastic natural products that serve as significant resources of pharmaceuticals for the treatment of various diseases, exhibiting properties such as anti-inflammatory, antibacterial, antifungal, antioxidation, anti-HIV, and immunity-enhancing properties [1]. To keep pace with the increasing commercial demand for triterpenoids, metabolic engineering of
\end{abstract}

(C) The Author(s) 2020. This article is licensed under a Creative Commons Attribution 4.0 International License, which permits use, sharing, adaptation, distribution and reproduction in any medium or format, as long as you give appropriate credit to the original author(s) and the source, provide a link to the Creative Commons licence, and indicate if changes were made. The images or other third party material in this article are included in the article's Creative Commons licence, unless indicated otherwise in a credit line to the material. If material is not included in the article's Creative Commons licence and your intended use is not permitted by statutory regulation or exceeds the permitted use, you will need to obtain permission directly from the copyright holder. To view a copy of this licence, visit http://creativeco mmons.org/licenses/by/4.0/. The Creative Commons Public Domain Dedication waiver (http://creativecommons.org/publicdomain/ zero/1.0/) applies to the data made available in this article, unless otherwise stated in a credit line to the data. 
cell factories has emerged as a promising and attractive alternative in industrial production and is an environmentally friendly and cost-efficient approach that is independent of plants [2].

Nevertheless, terpenoids, known for their in vivo antifungal activity, are generally highly toxic to microorganisms, inducing apoptosis and having a negative impact on terpene production [3-8]. For instance, lupeol, a typical triterpenoid, caused severe damage to cell viability even at a relatively low concentration of $60 \mathrm{mg} / \mathrm{L}[3,8]$. To decrease the intractable cytotoxicity, extensive efforts aimed at creating oleaginous subcellular organelles by altering lipid-droplet composition and size potentially improved the terpene partition coefficient in oil droplets and the storage space so that lipophilic terpenes can accumulate in these compartments [9-15]. For instance, researchers successfully increased lycopene accumulation by creating supersized lipid droplets through manipulation of triacylglycerol (TAG) metabolism in Saccharomyces cerevisiae, which resulted in the highest yield $(73.3 \mathrm{mg} / \mathrm{g} \mathrm{cdw}$ and $2.37 \mathrm{~g} / \mathrm{L}$ lycopene) reported in S. cerevisiae to date [10]. Similarly, knocking out POX1 to POX6 and GUT2 in Yarrowia lipolytica increased the size of lipid bodies, which enabled Y. lipolytica to withstand higher lycopene concentrations [11]. Gao et al. [12] successfully applied lipid droplets as a storage sink to enhance $\beta$-carotene production in Y. lipolytica, resulting in a $\beta$-carotene yield of up to $4 \mathrm{~g} / \mathrm{L}$ in fed-batch fermentation, the highest level attained so far.

Notably, the above strategies were biased toward the biosynthesis of tetraterpenoids with large molecules, which can accumulate in lipophilic compartments. However, terpenoids with relatively small molecules, such as triterpenes and flavonoids, are generally excreted into the extracellular space [16-18]. These products preferentially cross the plasma membrane via passive diffusion since the cell membrane is mainly composed of a lipid bimolecular layer [19]. As such, two-phase fermentation is widely utilized to extract terpenes from cells into extracellular lipophilic solvent and thus reduce product cytotoxicity [6]. However, the relatively low permeability of the cell membrane is still a barrier to the efflux of triterpenoids [19]. Manipulation of the lipid composition in membranes, such as the unsaturated fatty acid/saturated fatty acid (UFA/SFA) ratio or the membrane phospholipid content, is an efficient approach to tune membrane permeability and potentially alter the extra/intracellular partition coefficient of terpenes [15, 19-26]. For example, upregulation of SFA content in E. coli resulted in membrane tightening with enhanced tolerance to toxic $\mathrm{n}$-hexane in culture [25]. Besides, yeast cells can resist the damage caused by extracellular ethanol by altering membrane phospholipid properties [26]. However, these modifications are mostly adopted to reduce cell membrane permeability to block the entry of extracellular hazardous substances. Few applications are committed to promoting toxic terpene secretion through lipid regulation in microbial cell factories.

As a "generally regarded as safe" (GRAS) host, Y. lipolytica has emerged as an attractive host preferentially employed in the production of numerous pharmaceuticals and nutraceuticals [27]. The naturally high flux of acetyl-CoA in $Y$. lipolytica provides abundant terpene synthesis precursors. Moreover, Y. lipolytica is a remarkable oleaginous yeast in which lipid accumulation accounts for over $40 \%$ of the dry cell weight (DCW) [28]. The tractability of lipid metabolism in Y. lipolytica makes it a promising platform organism for terpene biosynthesis [9]. However, the cytotoxicity of terpenes with antimicrobial activities and the resulting metabolic burdens have led to great challenges in the biomanufacturing of terpenes in Y. lipolytica [3-5, 8, 28]. Herein, we applied a strategy of engineering lipid components to achieve high production of lupeol, a pentacyclic triterpene, in $Y$. lipolytica. Specifically, we (i) established a heterologous lupeol synthesis pathway in Y. lipolytica by chromosomally integrating genes encoding lupeol synthases from different sources, (ii) optimized the precursor supply by engineering structural genes in the mevalonate (MVA) pathway, (iii) significantly elevated lupeol biosynthesis by disturbing essential genes in lipid metabolism, and (iv) revealed accelerated export of lupeol caused by a twofold increase in the UFA proportion and markedly elongated cell morphology (Fig. 1). After doing so, the titer of lupeol in the organic phase was $381.67 \mathrm{mg} / \mathrm{L}$, and the total production reached $411.72 \mathrm{mg} / \mathrm{L}$ in shake flasks, representing the highest production reported to date. This strategy was also highly efficient for the biosynthesis of other triterpenes and sesquiterpenes, providing new insights for improving the production of valuable products in microbial cell factories.

\section{Results \\ Establishment of lupeol synthesis in Y. lipolytica}

Lupeol, a pentacyclic triterpene, is an important intermediate metabolite from the conversion of 2,3-oxidosqualene to a series of lupane-type triterpenoids and has attracted increasing attention due to its anti-HIV, anticancer and anti-inflammatory activities [3, 29, 30]. To produce lupeol from acetyl-CoA through the MVA pathway in $Y$. lipolytica, we assembled the following heterologous genes encoding lupeol synthases from different sources in strain ATCC 201249: AtLus from Arabidopsis thaliana, GuLus from Glycyrrhiza uralensis, OeLus from Olea europaea, BgLus from Bruguiera gymnorhiza, KdLus from Kalanchoe daigremontiana and RcLus from 

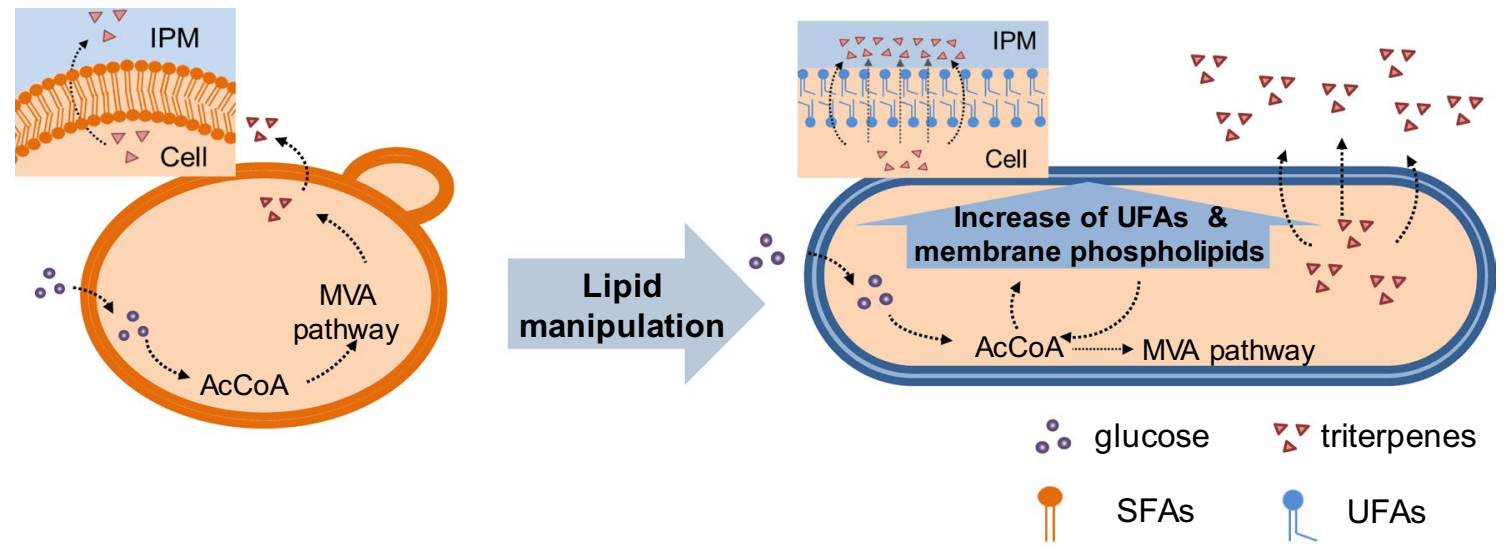

Fig. 1 Schematic diagram of lipid metabolism engineering to improve triterpene production in Y. lipolytica. The strains without lipid manipulation possessed relatively high levels of saturated fatty acids and exhibited spherical cells (left). After regulating lipid metabolism, the unsaturated fatty acid content increased twofold, and an elongated cell morphology was obtained, facilitating lupeol efflux from the cell to the lipophilic solvent isopropyl myristate, thereby improving cell activity and the capacity for single-cell triterpene synthesis (right). AcCoA, acetyl coenzyme A; UFAs, unsaturated fatty acids; SFAs, saturated fatty acids; IPM, isopropyl myristate

Ricinus communis. All of these genes were codon-optimized (Additional file 2: Table S1) and integrated into the $K u 70$ site in the genome of Y. lipolytica under the control of the Hp4d promoter. Then, we quantified lupeol production after 5 days of cultivation. Of these variants, strain LU-6 containing RcLus achieved the highest lupeol titer of $12.40 \mathrm{mg} / \mathrm{L}$ (Additional file 1: Fig. S1A) and was designated the initial strain.

Subsequently, we sought to improve the expression of RcLus by testing other promoters [31-33] (Additional file 1: Fig. S1B) and changed the subcellular locations of lupeol synthase by fusing different subcellular localization signal peptides to RcLus (Additional file 2: Table S2), which was confirmed by laser scanning confocal microscopy analysis (Additional file 1: Fig. S1C). Collectively, the strain LU-9 containing the RcLus gene expressed by the pTEFin promoter and localized in the cytosol achieved the highest lupeol titer of $29.00 \mathrm{mg} / \mathrm{L}$, a 2.33-fold increase compared with the initial strain LU-6 (Additional file 1: Fig. S1D). Thus, an optimized heterologous lupeol synthesis pathway was successfully established in Y. lipolytica. Strain LU-9 was selected for subsequent engineering and was designated the control strain in this study.

\section{Engineering of MVA and lipid metabolism to improve lupeol production}

To improve lupeol production, we first upregulated the MVA pathway by overexpressing the rate-limiting enzyme HMG1 (3-hydroxy-3-methylglutaryl coenzyme A reductase) [34, 35] in strain LU-9, generating strain LU-10. It has been reported that synchronous overexpression of ERG1 (squalene monooxygenase) and ERG9 (squalene synthase) [36] exhibited cooperativity toward enhancing terpene synthesis [37]. Hence, we further used this combination based on HMG1 overexpression to generate strain LU-11. In summary, HMG1 and $E R G 9$ were expressed by the pTEFin promoter, and ERG1 was controlled by the pEXP1 promoter, which was chromosomally integrated into the rDNA site of Y. lipolytica, marked with red rectangles in Fig. 2a. Compared with the control strain LU-9, the resulting strain LU-10 with single $H M G 1$ overexpression and LU-11 with HMG1, ERG9 and $E R G 1$ overexpression presented only slight improvement of lupeol yield at 1.21- and 1.56-fold, respectively (Fig. 2b). The achieved yield of lupeol in the present host was still at a low level, which is consistent with the effect on amorphadiene biosynthesis in Y. lipolytica [35]. These results revealed that MVA pathway modifications could not be the main factor that limited terpene overproduction in microorganisms; instead, the real rate-limiting step might be the downstream process, such as terpene synthesis, storage or transport.

Lipid metabolism was proven to be an effective strategy that can relieve the downstream bottleneck of terpene synthesis, including by extending the storage capacity of lipophilic products or improving terpene synthase efficiency, thereby promoting terpene overproduction [9-13]. As such, we manipulated eight structural and regulatory genes related to lipid metabolism in LU-9 (Fig. 2a), including $\beta$-oxidation disruption (by knocking out PXA1, MFE1, PEX10 or POT1) [38-40] and lipid synthesis regulation (by overexpressing the limiting step genes ACC1, OLE1 and its activator $M G A 2^{G 643 R}$ and 
a

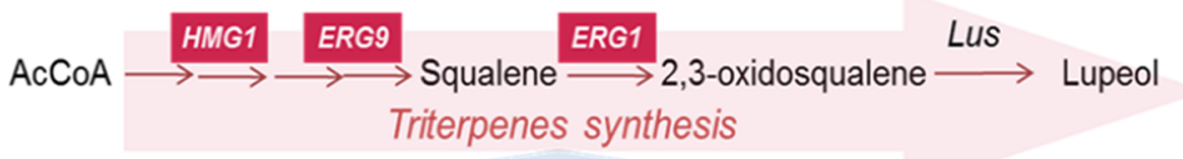

Triterpenes synthesis

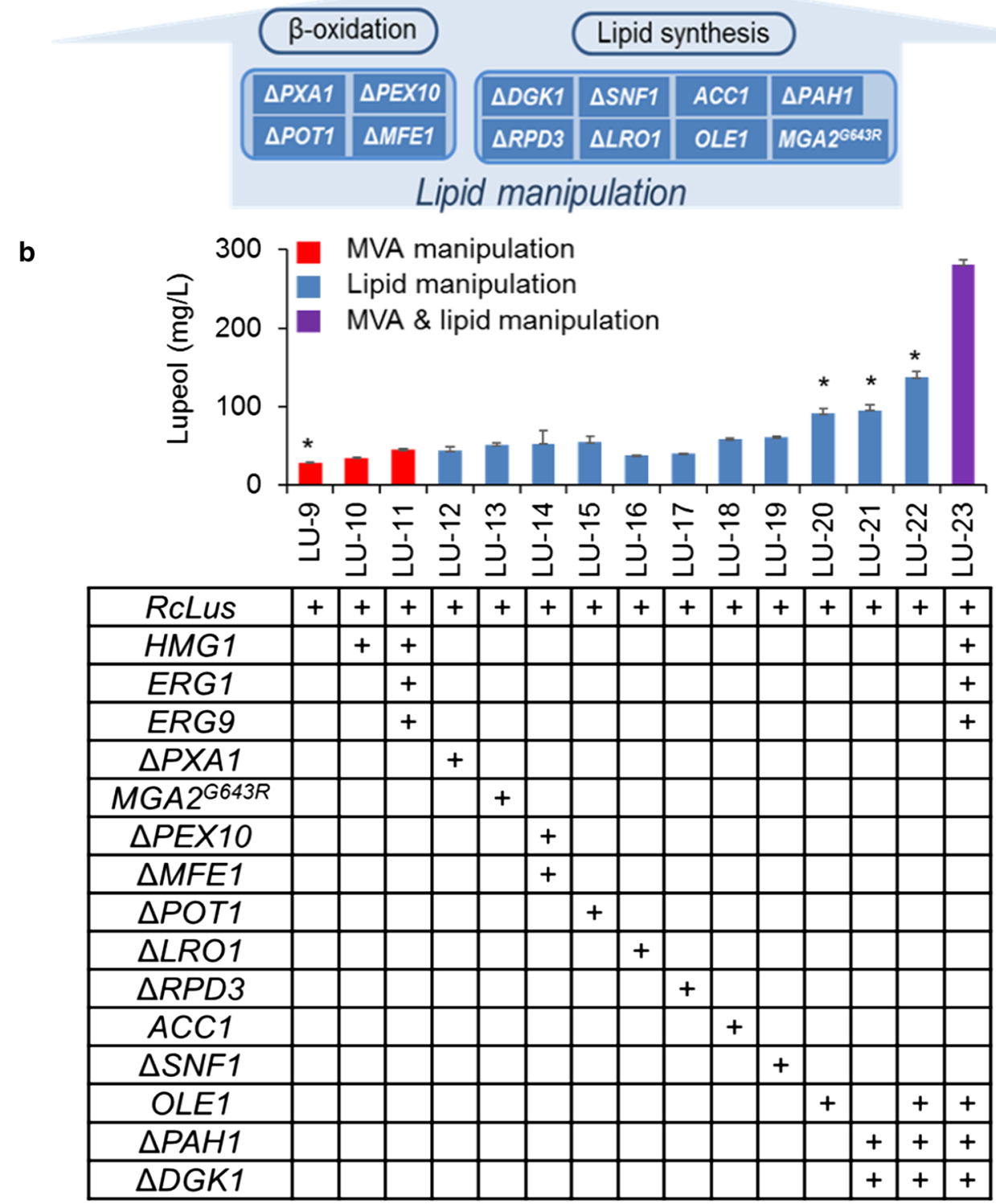

Fig. 2 Effect of metabolic engineering of the MVA pathway and lipid metabolism on lupeol production. a Related modified genes involved in the MVA biosynthesis pathway and lipid manipulation are represented by red rectangles and blue rectangles, respectively. b Lupeol production by engineered strains. The strains selected for further investigations are marked with asterisks. Error bars represent \pm SD of biological triplicates

disturbing the regulatory and structural genes $R P D 3$, SNF1, LRO1, PAH1 and DGK1) [41, 42] (Fig. 2a and Additional file 1: Fig. S2). Overexpression of each gene was performed by homologous recombination, and knockout of each gene was achieved by the CRISPR/Cas9 system, generating a series of strains from LU-12 to LU-21 based on LU-9. Among these strains, LU-20, with overexpression of OLE1, and LU-21, with knockout of PAH1-DGK1, promoted lupeol production most significantly, showing 3.16- and 3.30-fold improvement over strain LU-9, respectively. Then, a strain of LU-22 was generated by combination of overexpression of OLE1 and knockout of 
PAH1-DGK1, which further improved lupeol production to $137.52 \mathrm{mg} / \mathrm{L}, 4.74$-fold higher than the value for the strain LU-9.

Subsequently, manipulation of the MVA pathway and lipid metabolism were combined, generating strain LU-23 (with overexpression of RcLus, HMG1, ERG1, ERG9, and OLE1 and knockout of PAH1-DGK1). As shown in Fig. 2b, the production of lupeol in strain LU-23 reached $280.46 \mathrm{mg} / \mathrm{L}$ in shake flasks. Further improvement was achieved through optimization of the carbon source in the medium (Additional file 3), and the final lupeol production reached $411.72 \mathrm{mg} / \mathrm{L}$ (Additional file 1: Fig. S3), which was 33.20-fold higher than that in the initial strain LU-6 and 9.67-fold higher than that in the control strain LU-9.

In summary, boosting the flux of the MVA pathway by overexpressing rate-limiting enzymes (tHMG1, ERG1 and ERG9) only slightly enhanced lupeol biosynthesis. Lipid manipulation, however, had a marked effect on lupeol overproduction, especially the overexpression of OLE1 and the disruption of PAH1-DGK1. These three modified strains and the control strain LU-9 (marked with asterisks in Fig. 2b) were selected for further investigations to reveal the mechanism underlying the high production.

\section{Effect of overexpression of OLE1 and disruption of PAH1-DGK1 on the UFA proportion and cell morphology} To elucidate the underlying relationship between lupeol production and lipid regulation, we measured the lipid content and the composition of UFAs and SFAs in highproduction strains (LU-20, LU-21, and LU-22, marked with asterisks in Fig. 2b) and the control strain (LU-9). As shown in Fig. 3a, there was no obvious change in the total amount of fatty acids among the different strains. However, the UFA/SFA ratio was dramatically increased in all of the modified strains (Fig. 3b). The UFA content in the control strain (LU-9) was only $35 \%$, but the UFA proportions in all the high-production strains increased up to $61-73 \%$, approximately twofold higher than that in the control strain. These findings suggested that overexpressing OLE1 and knocking out PAH1-DGK1 mainly enhanced the proportion of UFAs instead of total fatty acid accumulation. The increased UFA proportion caused by OLE1 overexpression and PAH1-DGK1 knockout was consistent with previous studies [43-45]. The $O L E 1$ gene encodes a $\Delta 9$-fatty acid desaturase, which is mainly responsible for catalyzing the dehydrogenation of the 9-position in SFAs to form the related UFAs [43]. Moreover, knockout of $P A H 1$ could also result in increased levels of UFAs in yeast, even though this gene

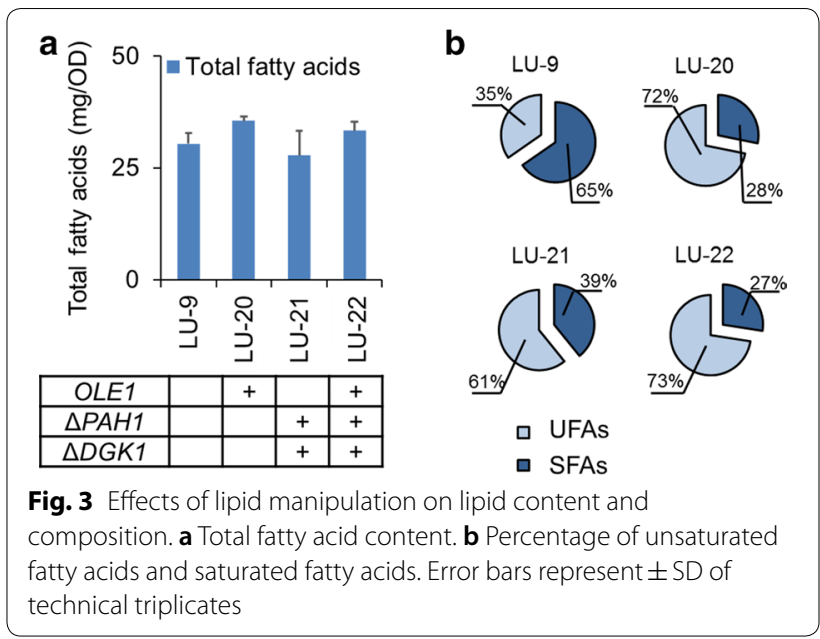

is responsible for phosphatidic acid (PA) transformation [44] (Additional file 1: Fig. S2).

In addition to the change in lipid components, we also observed that the morphologic profiles of PAH1-DGK1 knockout strains changed significantly. As detected by optical microscopy (Fig. 4a) and transmission electron microscopy (Fig. 4b), PAH1-DGK1 knockout in strains LU-21 and LU-22 resulted in extraordinarily elongated morphology, while strain LU-20 with OLE1 overexpression exhibited the same spherical cells as the control strain LU-9. The PAH1 knockout was also able to generate massive proliferation of ER membranes, providing more binding sites for ER-anchored enzymes to promote terpene biosynthesis [13]. However, no obvious ER proliferation in strains LU-20 and LU-21 with PAH1 knockout was observed by morphological analysis (Fig. 4b). As such, the effect of lipid modification on ER proliferation might not be the main factor associated with lupeol overproduction in this study.

The $P A H 1$ gene encodes a phosphatidate phosphatase [44]. Single knockout of $P A H 1$ caused shortening of the chronological life span and severe cell lethality, which could be rescued by knocking out $D G K 1$ with $P A H 1$ synchronously [44-46]. The transformation from PA to DAG was blocked with PAH1-DGK1 knockout, which could result in elevated levels of PA [44] and consequently lead to increased biosynthesis of phosphatidylserine (PS), phosphatidylethanolamine (PE), and phosphatidylcholine (PC) through the CDP-diacylglycerol (CDP-DAG) pathway [45]. We performed an RNA-seq analysis for the four strains, and as shown in Fig. 5, the genes related to the CDP-DAG pathway were obviously upregulated more than 1.50-fold in the PAH1-DGK1-deleted strain (LU-21 and LU-22) relative to the control strain (LU-9), including the genes encoding YALI0_C00209g (SCT1), 


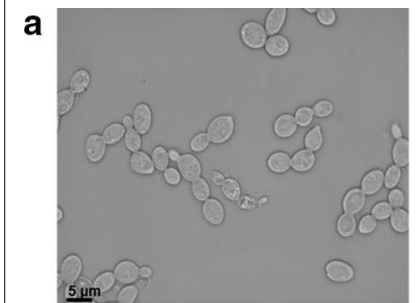

LU-9 (control)

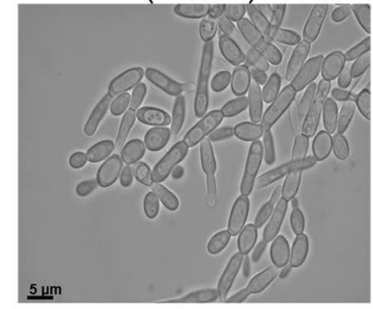

LU-21

( $\triangle P A H 1-\triangle D G K 1)$

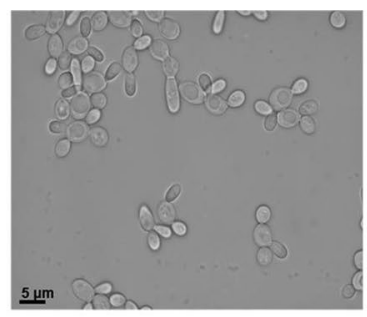

LU-20

(OLE1)

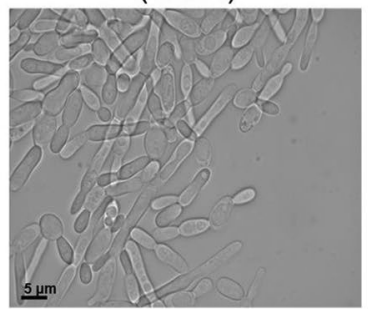

LU-22

(OLE1- $\triangle$ PAH1- $\triangle$ DGK1)

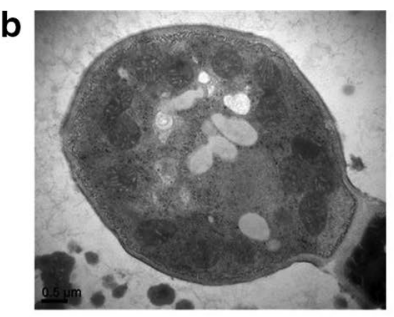

LU-9 (control)

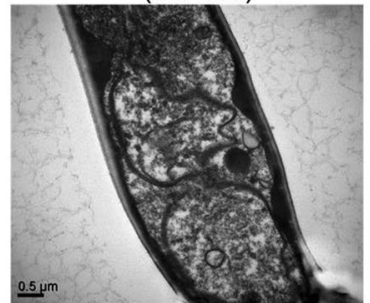

LU-21

( $\triangle P A H 1-\triangle D G K 1)$

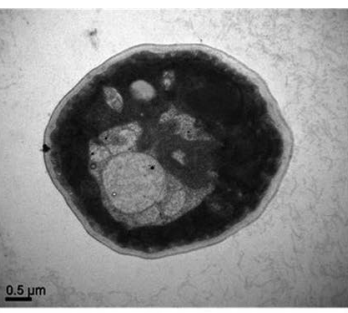

LU-20

(OLE1)

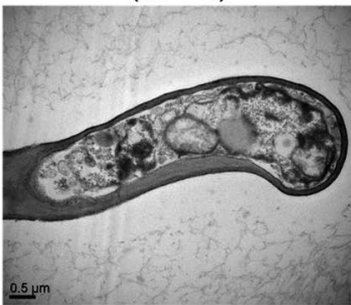

LU-22

(OLE1- $\triangle$ PAH1- $\triangle D G K 1)$

Fig. 4 Cell morphology of strains LU-9, LU-20, LU-21 and LU-22. a Morphological analysis by optical microscopy (scale bars, $5 \mu \mathrm{m}$ ). $\mathbf{b}$ Morphological analysis by transmission electron microscopy (scale bars, $0.5 \mu \mathrm{m}$ ). The strain LU-20 with OLE1 overexpression maintained a spherical morphology, which is similar to that of the control strain LU-9. However, disruption of PAH1-DGK1 in LU-21 and LU-22 led to a distinctive elongated morphology

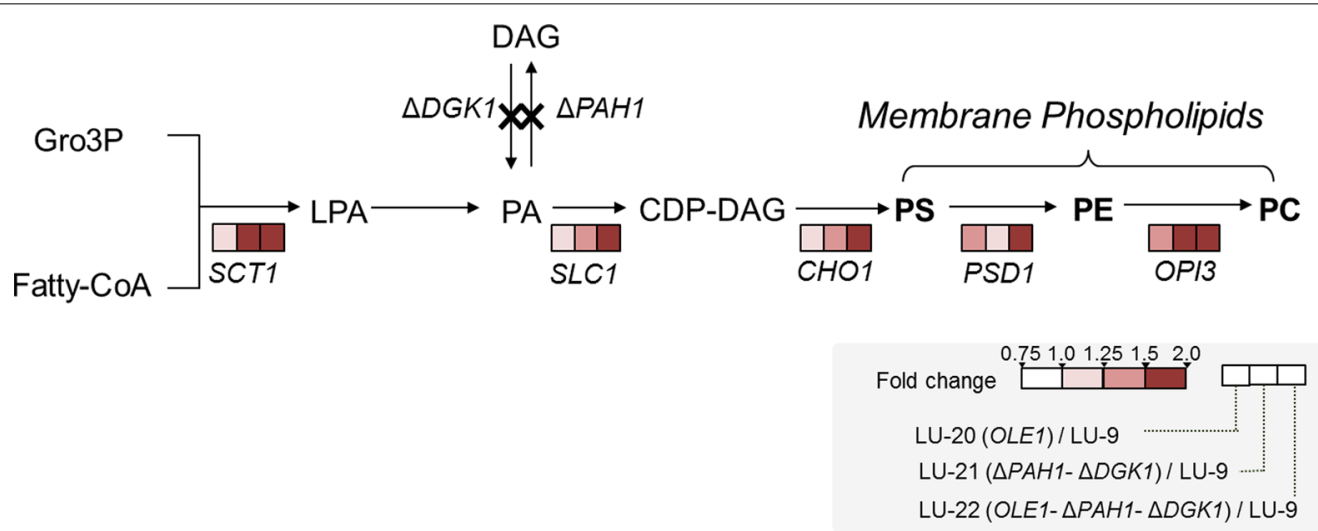

Fig. 5 Transcriptomic analysis of genes related to membrane phospholipid synthesis. The color in each rectangle and circle represents the change ratio of FPKM. Gro3P, glycerol-3-phosphate; LPA, lysophosphatidic acid; CDP-DAG, cytosine diphosphate-diacylglycerol; PS, phosphatidyl serine; PE, phosphatidyl ethanolamine; PC, phosphatidyl choline

YALIO_E18964g (SLC1), YALI0_D08514g (CHO1) and YALI0_E12441g (OPI3) (Additional file 2: Table S3). However, in the LU-20 strain, no similar upregulation of these genes was observed. The increased synthetic flux of PS, PE and PC, serving as the main components of membrane phospholipids, might result in accelerated synthesis of membrane phospholipids and is speculated to be the main factor underlying the elongated cell morphology of PAH1-DGK1 disruption strains.

Previous studies have demonstrated that elongated cell morphology might also be an indicator that cells might be experiencing a stress response, such as toxic product accumulation or lipid oxidation with increased UFA content $[47,48]$. To verify whether the cell morphology transition was induced by lupeol accumulation, we further analyzed the morphologic profiles of the strain by knocking out PAH1-DGK1 in ATCC 201249, generating strain LU-29. As shown in Additional file 1: Fig. S4, the cell membrane of strain LU-29 was still elongated without lupeol accumulation. In addition, strain LU-20, with high UFA content (up to $72 \%$ ), still exhibited spherical cells similar to those of the control strain LU-9. These 
results indicated that the elongated cell morphology was not induced by lupeol accumulation or UFA oxidation but rather by the genetic modification of lipid metabolism in this work.

In summary, OLE1 overexpression and PAH1-DGK1 disruption led to a marked change in lipid components. All three modified strains exhibited obviously increased proportions of UFAs instead of lipid accumulation. Knockout of PAH1-DGK1 elongated the cell morphology, which might have been caused by the enhanced flux of membrane phospholipid synthesis.

\section{Effect of lipid modifications on the efflux of metabolites}

Various studies have demonstrated that the increased UFA/SFA ratio disrupts the order of the phospholipid bilayer, contributing to the enhanced membrane permeability of toxic substances [19-24]. Meanwhile, the resulting cell elongation increased the contact area between the cells and the external environment. Both of the results described above are thought to have accelerated the efflux of products. To validate this hypothesis, we first tested the extra- and intracellular lupeol titers and analyzed the ratio of the extra/ intracellular lupeol content in two-phase extraction fermentations of LU-9, LU-20, LU-21 and LU-22 (Fig. 6a, b and Additional file 1: Fig. S5). Compared to LU-9, the total lupeol production and the extracellular lupeol titer in the engineered strains increased significantly, while there was no obvious change in lupeol accumulation intracellularly (Additional file 1: Fig. S5). Similarly, as shown in Fig. 6b, the ratio of the extra/ intracellular lupeol content also significantly increased to 13.71 in LU-20 with OLE1 overexpression and 9.71 in LU-21 with PAH1-DGK1 disruption, exhibiting 4.81- and 3.27-fold higher values than that in LU-9, in which the ratio was 2.81 . An optimal ratio of 14.38 was achieved in LU-22 with combinatorial engineering, 5.11-fold higher than that in LU-9. These results indicated that the lipid modifications indeed resulted in improvement of product efflux. Then, we determined the biomass growth and cell integrity. As shown in Fig. 6c, engineered cells grew much faster in the logarithmic phase, and the biomass accumulation of strains LU-20, LU-21 and LU-22 was 2.76-, 1.62- and 2.79-fold higher than that of strain LU-9, respectively. Cell integrity was also improved, as the propidium
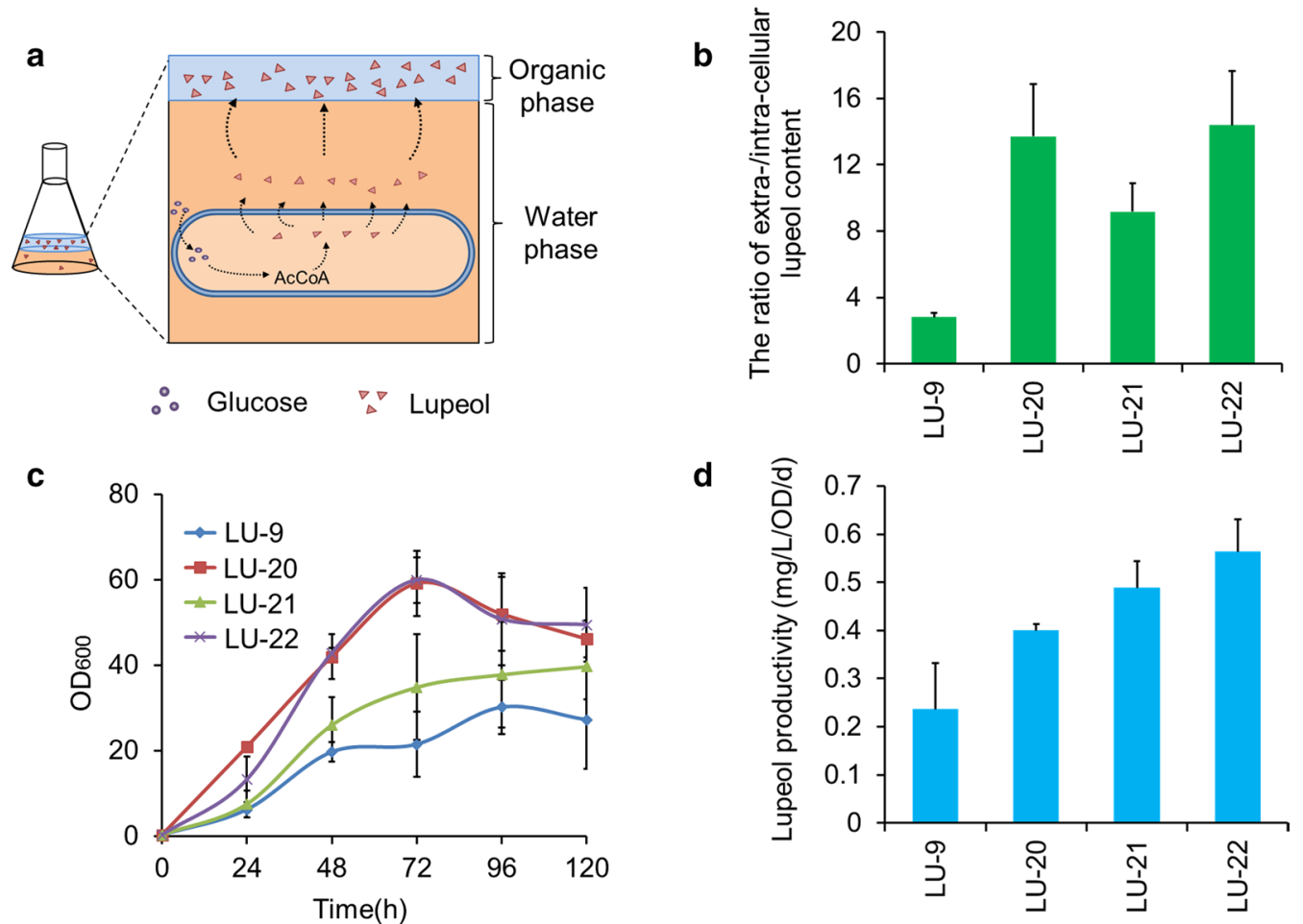

Fig. 6 Effect of lipid modifications on the efflux of lupeol during two-phase fermentation. a Schematic representation of two-phase extractive fermentation. $\mathbf{b}$ Ratio of the extra/intracellular lupeol content after $120 \mathrm{~h}$ of fermentation, calculated based on the lupeol titer as shown in Additional file 1: Fig. S5. c Effect of lipid modifications on cell growth. $\mathbf{d}$ Lupeol productivity after $120 \mathrm{~h}$ of fermentation. These results indicated that the efflux of lupeol was enhanced and ultimately improved cell growth and the capacity of lupeol synthesis in engineered strains. Error bars represent \pm SD of biological triplicates 
iodide (PI) uptake factor decreased in the engineered strains (Additional file 1: Fig. S6 and Additional file 3). These results confirmed that the improvement of lupeol efflux was beneficial to cell growth and integrity, indicating that cytotoxicity was indeed reduced in the engineered strains. We then calculated the lupeol productivity after $120 \mathrm{~h}$ of fermentation. As shown in Fig. 6d and Additional file 2: Table S4, notable improvements in lupeol-specific productivity in the engineered strains were also observed. Compared to $0.22 \mathrm{mg} / \mathrm{L} / \mathrm{OD} /$ days in strain LU-9, lupeol productivity increased to $0.40 \mathrm{mg} / \mathrm{L} / \mathrm{OD} /$ days, $0.49 \mathrm{mg} / \mathrm{L} / \mathrm{OD} /$ days and $0.56 \mathrm{mg} / \mathrm{L} / \mathrm{OD} /$ days in LU-20, LU-21 and LU-22, respectively, indicating that the capacity of lupeol synthesis was also apparently increased in the engineered strains. Notably, the improved lupeol productivity was induced by single-cell lupeol synthesis capacity but not the improvement of biomass growth.

Collectively, these results confirmed that the elevated UFA/SFA ratio and elongated cells significantly enhanced the export of lupeol, which contributed to higher cell growth and integrity and consequently enabled higher lupeol synthesis capacity.

\section{Effect of lipid modifications on the production of other terpenoid classes}

To test whether our strategy can be widely applied to enhance the production of other terpenoids, we first established the synthesis of two other kinds of triterpenoids ( $\alpha$ - and $\beta$-amyrin) by expressing $\alpha$-amyrin synthetase from Malus domestica $(\alpha A S)$ and $\beta$-amyrin synthetase from $A$. thaliana $(\beta A S)$, respectively [49] (Fig. 7a). Positive effects of lipid metabolism modification on $\alpha$-amyrin and $\beta$-amyrin production were obtained, with 1.76- and 8.83-fold improvement, respectively, in the titers compared to the parent strain (Fig. 7b). In addition to the triterpenoids, we further investigated the capacity of the lipid modifications for the production of sesquiterpenes. Longifolene class sesquiterpenoids, which serve as high-value therapeutic molecules, were employed [50] (Fig. 7c). The biosynthesis of longifolene, longipinene and longicyclene was realized by expressing terpene synthases (TPS) from Pinus sylvestris [51]. After

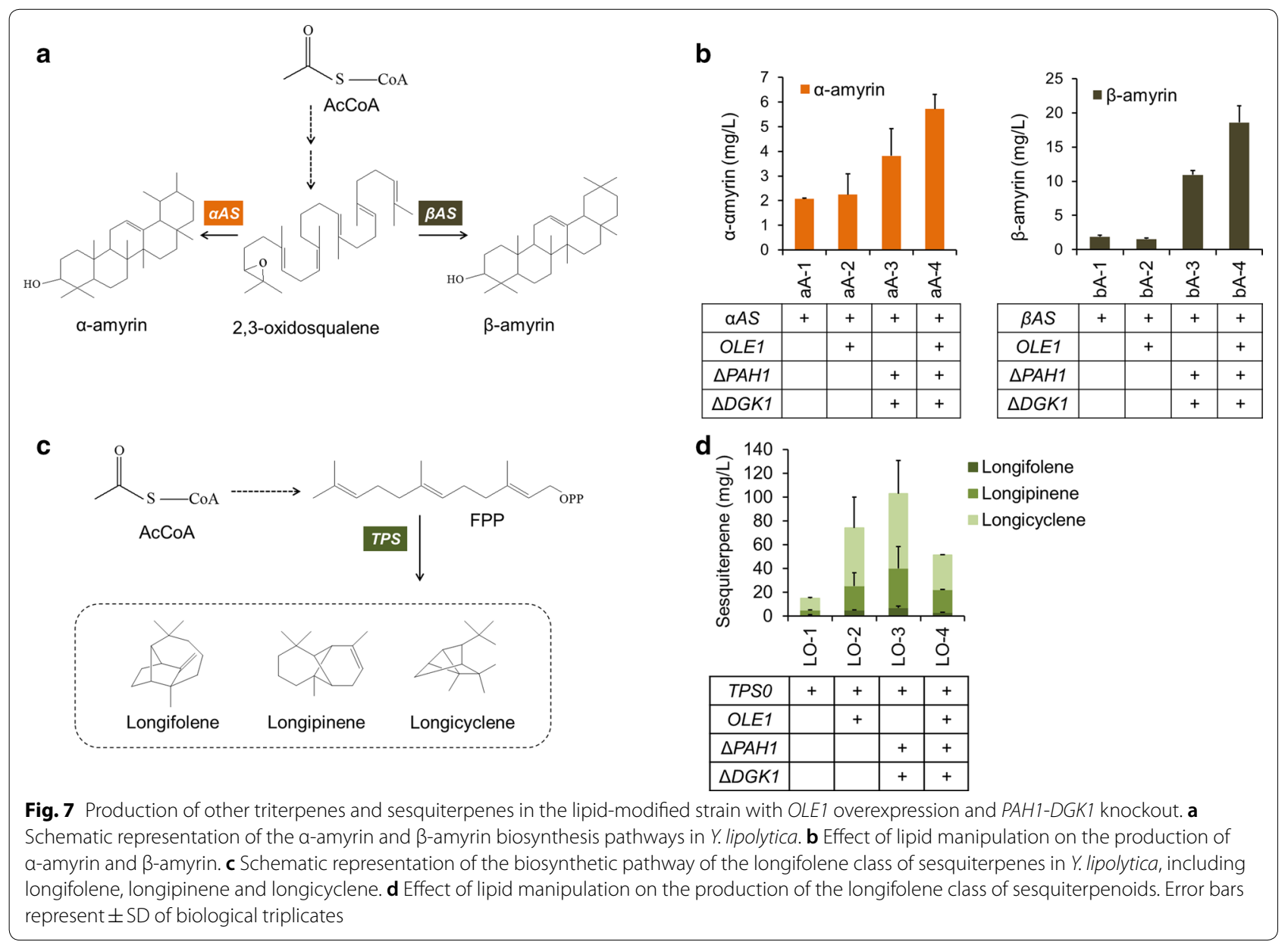


5 days of cultivation, obviously increased production was obtained in the lipid modification strain LO-3, with 5.68fold higher sesquiterpene production compared to the parent strain LO-1 (Fig. 7d).

\section{Discussion}

As a pentacyclic triterpenoid, lupeol has valuable pharmaceutical and nutraceutical properties $[3,8,30]$, but a severely negative impact of lupeol on cell viability was observed even at a relatively low concentration of $60 \mathrm{mg} / \mathrm{L}$ [3]. Y. lipolytica is emerging as a fascinating host for terpenoid biosynthesis, but the cytotoxicity of terpenes induced by their antimicrobial activities is still a main factor hampering terpene overproduction in Y. lipolytica $[4,5]$.

To improve lupeol production, a classic strategy that mainly boosts the flux of the MVA pathway was first employed by overexpressing rate-limiting enzymes (tHMG1, ERG1 and ERG9). However, lupeol production exhibited slight improvement, which is consistent with the results of the production of amorphadiene in Y. lipol$y$ tica [35]. In addition to the MVA pathway modifications, lipid manipulation was proven to be another promising alternative to accelerate the storage capacity for lipophilic products and ultimately promote their overproduction [9-14]. Increasing the UFA content in lipid droplets contributed to improving the solubility of highly lipophilic tetraterpenoids (such as lycopene and $\beta$-carotene) in oil droplets and thereby accelerated the intracellular accumulation of large-molecule terpenes [11, 14]. In contrast to previous studies, we creatively accelerated the efflux of relatively small molecular terpenes by altering lipid metabolism via OLE1 overexpression and PAH1-DGK1 knockout. The resulting increase in the UFA/SFA ratio contributed to enhancing the membrane permeability of toxic substances [52] and potentially increasing the extra/ intracellular partition coefficient of terpenoids with a highly nonpolar nature in the IPM phase [15].

Previous studies have demonstrated that the oxidation of UFAs or toxic chemical accumulation might induce a stress response and facilitate the cell morphology transition into a filamentous stage, consequently reducing cell viability and cell growth [47, 48]. However, the reason for the elongated cell morphology in this study was not lupeol accumulation, as the elongated cell morphology was still present in strain LU-29, which is a PAH1-DGK1 knockout strain that lacks the lupeol synthesis pathway. Cell elongation was not caused by oxidative stress with increasing UFA content because strain LU-20, with a high UFA content (72\%), exhibited the same spherical cells as the control strain LU-9. Moreover, the developed cell growth and improved cell integrity of the engineered strains also indicated that the cells did not experience a stress response. Therefore, the elongated cell morphology was the result of lipid metabolism via PAH1-DGK1 knockout.

\section{Conclusions}

In this study, we developed a strategy to create a highyield lupeol-producing strain via regulation of lipid components. Lipid manipulation significantly accelerated terpene excretion, enhancing the terpene synthesis capacity. The final lupeol production reached $411.72 \mathrm{mg} / \mathrm{L}$ in shake flasks, which is the highest lupeol yield reported to date. In addition, our strategy was also valid for overproduction of other triterpenes and sesquiterpenes. This work provides a novel and general strategy to improve the biosynthesis of valuable but toxic terpene products in microbial cell factories.

\section{Methods}

\section{Strains, media and culture conditions}

The Y. lipolytica strain ATCC 201249 (MATA, ura3-302, leu2-270, lys8-11, PEX17-HA) was chosen as the background strain [53] for all constructs, and the genotypes of all the derivatives constructed in the present study are listed in Additional file 2: Table S5. The above Y. lipolytica strains were cultivated in yeast medium at $28{ }^{\circ} \mathrm{C}$ at a shaking speed of $250 \mathrm{rpm}$. The rich YPD medium containing $50 \mathrm{~g} / \mathrm{L}$ glucose, $20 \mathrm{~g} / \mathrm{L}$ peptone, and $10 \mathrm{~g} / \mathrm{L}$ yeast extract was used for cultivation and fermentation of $Y$. lipolytica strains. The SC medium, used for screening $Y$. lipolytica transformants, contained $20 \mathrm{~g} / \mathrm{L}$ glucose, $6.7 \mathrm{~g} / \mathrm{L}$ yeast nitrogen base without amino acids, and $2 \mathrm{~g} / \mathrm{L}$ complete supplement mixture (CSM) lacking uracil (SC-Ura) or leucine (SC-Leu), supplemented with uracil or leucine depending on the selection marker requirements. If necessary, an appropriate amount of hygromycin B (final concentration $100 \mathrm{mg} / \mathrm{L}$ ) was added at $50-60{ }^{\circ} \mathrm{C}$ for screening of recombinant strains containing the hygromycin resistance gene (Hph). DH5 $\mathrm{E}$. coli was used for routine plasmid propagation and construction of recombinant vectors and grown in Luria-Bertani broth at $37^{\circ} \mathrm{C}$ with a shaking speed of $250 \mathrm{rpm}$. Suitable antibiotics were added when necessary at the following final concentrations: ampicillin at $100 \mathrm{mg} / \mathrm{L}$ or kanamycin at $50 \mathrm{mg} / \mathrm{L}$. Agar $(20 \mathrm{~g} / \mathrm{L})$ was added for solid plate preparation.

For terpene shake flask fermentation, freshly streaked single colonies of strains were first cultivated in $25-\mathrm{mL}$ polypropylene tubes with $5 \mathrm{~mL}$ of YPD medium and cultured at $28^{\circ} \mathrm{C}$ with a shaking speed of $250 \mathrm{rpm}$ overnight. After preculturing, the seed cultures were inoculated into $50 \mathrm{~mL}$ of fresh YPD medium with an initial $\mathrm{OD}_{600}$ of 0.2 and fermented in a $250-\mathrm{mL}$ shake flask for $120 \mathrm{~h}$. 
Ten milliliters of isopropyl myristate (IPM) was added for two-phase extraction fermentation to reduce the toxicity inhibition of steroid products on cell growth. All flask fermentations were performed in triplicate.

\section{Strain and plasmid construction and yeast transformation}

All plasmids and primers applied in this work are listed in Additional file 2: Tables S6 and S7, respectively. All the enzymes involved in this study were obtained from New England Biolabs (NEB, USA). The TIANprep Mini Plasmid Kit and TIANgal Midi Purification Kit were used for plasmid extraction and DNA fragment purification, respectively, and the Zymogen Frozen EZ Yeast Transformation Kit II (Zymo Research Corporation) was employed for $Y$. lipolytica transformation. The relevant processes were carried out in accordance with the manufacturer's instructions.

Six exogenous lupeol synthase-coding genes (AtLus from A. thaliana, GuLus from G. uralensis, OeLus from O. europaea, BgLus from B. gymnorhiza, KdLus from $K$. daigremontiana and RcLus from $R$. communis) were codon-optimized and synthesized by GenScript (Nanjing, China) (codon-optimized sequences in Additional file 2: Table S1). Three native genes in the MVA pathway, namely HMG1 (3-hydroxy-3-methylglutaryl coenzyme A reductase), ERG9 (squalene synthase), and ERG1 (squalene monooxygenase), and three native genes in the lipid metabolism pathway, namely, ACC1 (acetylCoA carboxylase from $Y$. lipolytica), OLE1 ( $\triangle 9$-fatty acid desaturase) and its activator MGA2 substitution $M G A 2^{G 643 R}$, were amplified from $Y$. lipolytica genomic DNA by a normal polymerase chain reaction (PCR) method using the primers listed in Additional file 2: Table S7. All of these genes were cloned into the expression plasmids at the corresponding sites with different promoters and the LEU2, URA3 or Hph marker. The resulting recombinant plasmids were digested with NotI and purified on a gel. Then, approximately $2 \mu \mathrm{g}$ of linearized DNA was used in the transformation reaction, and the transformants were centrifuged at $6000 \times g$ for $2 \mathrm{~min}$, plated on SC agar plates without the auxotrophic compound supplemented by the corresponding markers, and cultured at $28{ }^{\circ} \mathrm{C}$ for $2-3$ days. Positive transformants were confirmed by colony PCR with KOD FX DNA polymerase (Toyobo Co., Ltd.; Shanghai, China). Removal of the Ura3 selection marker was carried out by shaking the transformants in YPD liquid medium for 2-3 days and then incubating the transformants on YPD solid medium containing $1.2 \mathrm{mg} / \mathrm{mL} 5$-fluoroorotic acid for 2 days. The obtained colonies were then streaked onto SC and SCUra plates and incubated at $28^{\circ} \mathrm{C}$ for $2-3$ days.

Disruption of target genes in Y. lipolytica was achieved by the CRISPR system [27], which has been widely used in various studies. The plasmid pMCS-Cen 1 was used to construct the CRISPR-Cas9 system. The synthesized gRNA was incorporated into pMCS-Cen1-URA, and then, the resulting plasmids were digested with the restriction enzymes BamHI and HindIII followed by ligation with a segment of Cas9, thereby forming the corresponding plasmids. For CRISPR plasmid transformations, $Y$. lipolytica cells were transformed with the corresponding plasmids and cultivated in SC-Ura liquid medium for 4 days. Then, the cells were plated onto SCUra plates and cultured for 2 days at $28^{\circ} \mathrm{C}$ and confirmed via sequencing analysis.

\section{Extraction and analysis of triterpenoids (lupeol, $a$-amyrin, and $\beta$-amyrin) and sesquiterpenes (longifolene, longicyclene and longipinene)}

The extraction of triterpenes (lupeol, $\alpha$-amyrin, $\beta$-amyrin) and sesquiterpene products (longifolene, longifolene, longifolene) is mainly divided into organicphase and cell-phase extraction. For the organic-phase sample, the two-phase fermentation broth was centrifuged at $5000 \mathrm{rpm}$ for $5 \mathrm{~min}$, and then, the supernatant was filtered by a $0.22-\mu \mathrm{m}$ polypropylene organic filter for extracellular terpenoid detection. The precipitate was prepared for the extraction of cell-phase samples. After centrifugation and washing 3 times with distilled water to ensure adequate removal of the residual organic phase, the precipitate was mixed with $0.5 \mathrm{~mL}$ of ethyl acetate and $0.1 \mathrm{~mL}$ of quartz sand and then vortexed for $20 \mathrm{~min}$. After centrifugation at 15,000 rpm for $15 \mathrm{~min}$, the organic mixture was filtered through a $0.22-\mu \mathrm{m}$ organic filter membrane. Appropriate concentrations of lupeol (Aladdin Industrial Corporation, USA), $\alpha$-amyrin, $\beta$-amyrin (Sigma-Aldrich Corporation, USA) and longicyclene (Shanghai Yuanye Bio-technology Corporation, China) were dissolved in IPM as external standards to ensure the production of terpenoids. All of the final samples in two phases were stored at $-80^{\circ} \mathrm{C}$.

The methods for the analysis of terpenoids by gas chromatography-mass spectrometry (GC-MS) were modified based on those reported in a previous study [37]. The combination of a GC-MS system equipped with a DB-5MS GC column $(30 \mathrm{~m} \times 0.25 \mathrm{~mm} \times 0.5 \mu \mathrm{m})$ and Masslynx software (Version 4.1, Waters Corp., USA) was applied for qualitative and quantitative analysis of triterpenoids. The details of the analysis process are as follows. For the GC system, $1 \mu \mathrm{L}$ of the obtained sample was injected by an Agilent 7683 autosampler under a split ratio of 10 , and the temperature of the injector and GC interface was $250{ }^{\circ} \mathrm{C}$. The carrier gas was highpurity helium with a constant flow of $1.2 \mathrm{~mL} / \mathrm{min}$. After 2 min at $80^{\circ} \mathrm{C}$, the column temperature was increased at 
a speed of $20{ }^{\circ} \mathrm{C} / \mathrm{min}$ to $300{ }^{\circ} \mathrm{C}$, holding at this temperature for $17 \mathrm{~min}$. For the MS system, the temperature of ion source was $230{ }^{\circ} \mathrm{C}$, and full scan mode was used from 50 to $700 \mathrm{~m} / z$.

For the analysis of sesquiterpenes, some parameters were adjusted as follows. For the GC system, the split ratio and the temperature of the injector and GC interface were adjusted to 50 and $250{ }^{\circ} \mathrm{C}$, respectively. The carrier gas was high-purity helium with a constant flow of $2 \mathrm{~mL} / \mathrm{min}$. After $2 \mathrm{~min}$ at $40{ }^{\circ} \mathrm{C}$, the column temperature was increased to $210{ }^{\circ} \mathrm{C}$ at a speed of $20{ }^{\circ} \mathrm{C} / \mathrm{min}$, followed by increasing to $300{ }^{\circ} \mathrm{C}$ at a speed of $60{ }^{\circ} \mathrm{C} / \mathrm{min}$ and holding for $2 \mathrm{~min}$. For the MS system, the ion source temperature was set at $220{ }^{\circ} \mathrm{C}$, and the scanning range parameter was $35-500 \mathrm{~m} / \mathrm{z}$.

\section{Extraction and analysis of total fatty acids}

For total fatty acid extraction, fresh samples of cell cultures were harvested after $120 \mathrm{~h}$ of fermentation (three duplicates). After centrifugation and washing 3 times with distilled water, $1 \mathrm{~mL}$ of methanol solution containing $3 \mathrm{M}$ hydrogen chloride, $0.1 \mathrm{~mL}$ of chloroform and 5 $\mu \mathrm{L}$ of heptadecanoic acids as an internal standard (final concentration of $200 \mathrm{mg} / \mathrm{L}$ ) was added into the precipitate, followed by incubation at $70{ }^{\circ} \mathrm{C}$ for $3 \mathrm{~h}$, mixing by inversion every $40 \mathrm{~min}$. After naturally cooling the samples to room temperature, $0.2 \mathrm{~mL}$ of sodium chloride particles was added, and the samples were vortexed for $1 \mathrm{~min}$, followed by the addition of $0.5 \mathrm{~mL}$ of the organic solvent $n$-hexane and vortexing for $3 \mathrm{~min}$. After centrifugation at 12,000 rpm for $5 \mathrm{~min}$, the upper organic phase was filtered with a $0.22-\mu \mathrm{m}$ organic film and stored at $-80^{\circ} \mathrm{C}$, ready for the detection of total fatty acid concentration by GC-MS.

The method used for the analysis of total fatty acids by GC-MS was similar to the methods reported previously [54]. For the GC system, $1 \mu \mathrm{L}$ of the obtained sample was injected by an Agilent 7683 autosampler under a split ratio of 2, and the temperatures of the injector and GC interface were both $280^{\circ} \mathrm{C}$. The carrier gas was highpurity helium with a constant pressure of $91 \mathrm{kPa}$. After 2 min at $70{ }^{\circ} \mathrm{C}$, the column temperature was increased at a speed of $8{ }^{\circ} \mathrm{C} / \mathrm{min}$ to $290^{\circ} \mathrm{C}$, holding at this temperature for $6 \mathrm{~min}$. For the MS system, the ion source temperature was set at $250{ }^{\circ} \mathrm{C}$, and the scanning range parameter was $50-800 \mathrm{~m} / \mathrm{z}$.

\section{RNA-seq analysis}

Culture samples were collected at logarithmic phase (two parallel measurements) after centrifugation at $5000 \mathrm{rpm}$ for 2 min, washed with PBS solution 3 times and quickly frozen with liquid nitrogen after centrifugation. The acquisition, analysis and sequencing of mRNA from the above samples were performed by Beijing Genomics Institute (BGI). Library construction was performed using cDNA, which was generated from mRNA after fragmentation and reverse transcription by N6 primers. Then, the library quality was determined using a Bioanalyzer 2100 (Agilent) analyzer, and the libraries were sequenced on the BGISEQ-500 sequencing platform. The sequencing reads were filtered and stored in FASTQ format. The relative expression of genes was calculated using RSEM software and the FPKM method. Finally, indepth data analysis was performed on the BGI data analysis platform (http://report.bgi.com/ps/login/login.html).

\section{Morphological analysis by transmission electron microscopy}

Cells were harvested, and the supernatant was discarded after centrifugation at $5000 \mathrm{rpm}$ for $2 \mathrm{~min}$, followed by resuspension and fixation with $2.5 \%$ glutaraldehyde solution overnight $\left(4{ }^{\circ} \mathrm{C}\right)$. The mixture was rinsed three times with $0.1 \mathrm{M}$ PBS for $15 \mathrm{~min}$, fixed with $1 \%$ osmic acid for 1 to $2 \mathrm{~h}$ and then rinsed three times with 0.1 M PBS. Then, the obtained sample was dehydrated by ethanol solutions with concentrations of $30 \%, 50 \%, 70 \%, 80 \%, 90 \%$, and $95 \%$, successively, and then treated as follows: $100 \%$ ethanol for $20 \mathrm{~min}$, acetone solution for $20 \mathrm{~min}$, acetoneembedding agent $(V / V=1 / 1)$ mixed solution for $1 \mathrm{~h}$, acetone-embedding agent $(V / V=3 / 1)$ mixed solution for $3 \mathrm{~h}$, and pure embedding agent for $12 \mathrm{~h}$. After heating at $70^{\circ} \mathrm{C}$ for $12 \mathrm{~h}$, the embedded sample was sectioned with a Leica EM UC7 ultrathin microtome (70-90 nm), stained with lead citrate and $50 \%$ uranyl acetate ethanol solution for $5 \mathrm{~min}$, and then observed with a transmission electron microscope.

\section{Supplementary information}

Supplementary information accompanies this paper at https://doi. org/10.1186/s13068-020-01773-1.

Additional file 1: Fig. S1. Optimization of the heterologous lupeol synthesis pathway in Y. lipolytica. (A) Relative lupeol production by lupeol synthases from different sources. (B) Lupeol production by the identified gene RCLus under the control of different promoters. (C) Microscopic images of strains modified with the sfGFP gene by fusing different subcellular localization signal peptides. Cells were observed by laser scanning confocal microscopy. (D) Effect of different subcellular locations on lupeol production. Abbreviations: Mit, mitochondria; Per, peroxisome; ER, endoplasmic reticulum. Error bars represent $\pm S D$ of technical triplicates. Fig. S2. Schematic representation of key genes associated with lipid metabolism in $Y$. lipolytica. All genes in blue rectangles were regulated in this study. Red arrows represent relative pathway upregulation, and red crosses represent relative pathway deletion. Red circles indicate mutual inhibition between genes. Green circles indicate mutual promotion between genes. Fig. S3. Culture optimization for LU-23 lupeol production in shake flasks. (A) Effect of carbon optimization and (B) heterologous addition of pyruvic acid on lupeol yield. Error bars represent \pm SD of technical triplicates. Fig. S4. Cell morphology of strain LU-29. Morphological analysis by optical microscopy (scale bars, $5 \mu \mathrm{m}$ ). The strain LU-29 without the lupeol synthesis pathway also exhibited a distinctive elongated morphology, indicating that the cell 
morphology transition had little relation with lupeol accumulation. Fig. S5. Extracellular and intracellular lupeol titers after $120 \mathrm{~h}$ of fermentation. Compared with LU-9, the total lupeol production and the extracellular lupeol titer increased significantly in the engineered strains, while there was no obvious change in intracellular lupeol accumulation. These results indicated that the lupeol was discharged out of the cell more efficiently. Error bars represent $\pm S D$ of biotechnical triplicates. Fig. S6. Cell integrity in the stationary phase after $120 \mathrm{~h}$ of fermentation. Cell integrity was measured by the propidium iodide (PI) staining method, in which as cell integrity increases, Pl uptake decreases. Compared to the control strain LU-9, all of the modified strains exhibited improved cell integrity with decreased PI uptake. Error bars represent \pm SD of biotechnical triplicates.

Additional file 2: Table S1. Codon-optimized gene sequences involved in this study. Table S2. Subcellular targeting signal peptides used in this study. Table S3. Upregulated genes in the membrane phospholipid synthesis pathway. Table S4. Lupeol yield and productivity in selected strains. Table S5. Strains used in this study. Table S6. Plasmids used in this study. Table S7. Primer sequences used in this study.

Additional file 3: Methods. Culture optimization and cell integrity analysis.

\section{Acknowledgements}

The authors are grateful for the Major Program of the National Natural Science Foundation of China (Major Program: 21621004), the Natural Science Foundation of Tianjin City (19JCQNJC09200) and the Young Elite Scientists Sponsorship Program by Tianjin (TJSQNTJ-2018-16).

\section{Authors' contributions}

$J L Z$ and QYB designed the project, performed experiments, analyzed data, and drafted the manuscript. YZP, JF and CCJ performed experiments. YXC designed and supervised the project, analyzed data, and critically revised the manuscript. YJY supervised the project. All authors read and approved the final manuscript.

\section{Funding}

Major Program of the National Natural Science Foundation of China (Major Program: 21621004), Natural Science Foundation of Tianjin City (19JCQNJC09200) and the Young Elite Scientists Sponsorship Program by Tianjin (TJSQNTJ-2018-16).

\section{Availability of data and materials}

Data will be made available from the corresponding author on reasonable request.

\section{Ethics approval and consent to participate}

Not applicable.

\section{Competing interests}

The authors declare that they have no competing interests.

\section{Author details}

${ }^{1}$ Frontier Science Center for Synthetic Biology and Key Laboratory of Systems Bioengineering (Ministry of Education), School of Chemical Engineering and Technology, Tianjin University, Tianjin 300072, China. ${ }^{2}$ Collaborative Innovation Center of Chemical Science and Engineering (Tianjin), Tianjin University, Tianjin 300072, China.

Received: 31 March 2020 Accepted: 20 July 2020

Published online: 29 July 2020

\section{References}

1. Bishayee A, Ahmed S, Brankov N, Perloff M. Triterpenoids as potential agents for the chemoprevention and therapy of breast cancer. Front Biosci (Landmark Ed). 2011;16:980-96.

2. Teijaro CN, Adhikari A, Shen B. Challenges and opportunities for natural product discovery, production, and engineering in native producers versus heterologous hosts. J Ind Microbiol Biotechnol. 2019;46(3-4):433-44.

3. Guo MB, Wang DC, Liu HF, Chen LW, Wei JW, Lin Y, et al. Lupeol against high-glucose-induced apoptosis via enhancing the anti-oxidative stress in rabbit nucleus pulposus cells. Eur Spine J. 2018;27(10):2609-20.

4. Worland AM, Czajka JJ, Li Y, Wang Y, Tang YJ, Su WW. Biosynthesis of terpene compounds using the non-model yeast Yarrowia lipolytica: grand challenges and a few perspectives. Curr Opin Biotechnol. 2020;64:134-40.

5. Zieniuk B, Fabiszewska A. Yarrowia lipolytica: a beneficious yeast in biotechnology as a rare opportunistic fungal pathogen: a minireview. World J Microbiol Biotechnol. 2018;35(1):10.

6. Brennan TC, Turner CD, Krömer JO, Nielsen LK. Alleviating monoterpene toxicity using a two-phase extractive fermentation for the bioproduction of jet fuel mixtures in Saccharomyces cerevisiae. Biotechnol Bioeng. 2012;109(10):2513-22.

7. Verwaal R, Jiang Y, Wang J, Daran JM, Sandmann G, van den Berg J, et al. Heterologous carotenoid production in Saccharomyces cerevisiae induces the pleiotropic drug resistance stress response. Yeast. 2010;27(12):983-98.

8. Siddique HR, Saleem M. Beneficial health effects of lupeol triterpene: a review of preclinical studies. Life Sci. 2011;88(7-8):285-93.

9. Larroude M, Celinska E, Back A, Thomas S, Nicaud JM, Ledesma-Amaro R. A synthetic biology approach to transform Yarrowia lipolytica into a competitive biotechnological producer of $\beta$-carotene. Biotechnol Bioeng. 2018;115(2):464-72.

10. Ma T, Shi B, Ye Z, Li X, Liu M, Chen Y, et al. Lipid engineering combined with systematic metabolic engineering of Saccharomyces cerevisiae for high-yield production of lycopene. Metab Eng. 2019;52:134-42.

11. Matthäus F, Ketelhot M, Gatter M, Barth G. Production of lycopene in the non-carotenoid-producing yeast Yarrowia lipolytica. Appl Environ Microbiol. 2014;80(5):1660-9.

12. Gao S, Tong Y, Zhu L, Ge M, Zhang Y, Chen D, et al. Iterative integration of multiple-copy pathway genes in Yarrowia lipolytica for heterologous $\beta$-carotene production. Metab Eng. 2017;41:192-201.

13. Arendt P, Miettinen K, Pollier J, De Rycke R, Callewaert N, Goossens A. An endoplasmic reticulum-engineered yeast platform for overproduction of triterpenoids. Metab Eng. 2017;40:165-75.

14. Sun Y, Sun L, Shang F, Yan G. Enhanced production of beta-carotene in recombinant Saccharomyces cerevisiae by inverse metabolic engineering with supplementation of unsaturated fatty acids. Process Biochem. 2016;51(5):568-77.

15. Mendanha SA, Alonso A. Effects of terpenes on fluidity and lipid extraction in phospholipid membranes. Biophys Chem. 2015;198:45-54.

16. Dunlop MJ, Dossani ZY, Szmidt HL, Chu HC, Lee TS, Keasling JD, et al. Engineering microbial biofuel tolerance and export using efflux pumps. Mol Syst Biol. 2011;7:487.

17. Langevin AM, Dunlop MJ. Stress introduction rate alters the benefit of acrab-tolc efflux pumps. J Bacteriol. 2018;200(1):e00525-617.

18. Xie W, Ye L, Lv X, Xu H, Yu H. Sequential control of biosynthetic pathways for balanced utilization of metabolic intermediates in Saccharomyces cerevisiae. Metab Eng. 2015;28:8-18.

19. Pérez-Sánchez A, Borrás-Linares I, Barrajón-Catalán E, Arráez-Román D, González-Álvarez I, Ibáñez E, et al. Evaluation of the intestinal permeability of rosemary (Rosmarinus officinalis $L$ ) extract polyphenols and terpenoids in Caco-2 cell monolayers. PLoS ONE. 2017;12(2):e0172063.

20. Westbrook AW, Ren X, Moo-Young M, Chou CP. Engineering of cell membrane to enhance heterologous production of hyaluronic acid in Bacillus subtilis. Biotechnol Bioeng. 2018;115(1):216-31.

21. Hagve TA. Effects of unsaturated fatty acids on cell membrane functions. Scand J Clin Lab Invest. 1988;48(5):381-8.

22. Qi Y, Liu H, Chen $X$, Liu L. Engineering microbial membranes to increase stress tolerance of industrial strains. Metab Eng. 2019;53:24-34.

23. Yang $X$, Sheng W, Sun GY, Lee JC. Effects of fatty acid unsaturation numbers on membrane fluidity and a-secretase-dependent amyloid precursor protein processing. Neurochem Int. 2011;58(3):321-9.

24. Sezgin E, Levental I, Mayor S, Eggeling C. The mystery of membrane organization: composition, regulation and roles of lipid rafts. Nat Rev Mol Cell Biol. 2017;18(6):361-74.

25. Oh HY, Lee JO, Kim OB. Increase of organic solvent tolerance of Escherichia coli by the deletion of two regulator genes, fadR and marR. Appl Microbiol Biotechnol. 2012;96(6):1619-27. 
26. Konas RM, Daristotle JL, Harbor NB, Klauda JB. Biophysical changes of lipid membranes in the presence of ethanol at varying concentrations. J Phys Chem B. 2015;119(41):13134-41.

27. Zhang JL, Peng YZ, Liu D, Liu H, Cao YX, Li BZ, et al. Gene repression via multiplex gRNA strategy in Y. lipolytica. Microb Cell Fact. 2018;17(1):62.

28. Xu P, Qiao K, Ahn WS, Stephanopoulos G. Engineering Yarrowia lipolytica as a platform for synthesis of drop-in transportation fuels and oleochemicals. Proc Natl Acad Sci USA. 2016;113(39):10848-53.

29. Pandey H, Pandey P, Singh S, Gupta R, Banerjee S. Production of anti-cancer triterpene (betulinic acid) from callus cultures of different Ocimum species and its elicitation. Protoplasma. 2015;252(2):647-55.

30. Tsai FS, Lin LW, Wu CR. Lupeol and its role in chronic diseases. Adv Exp Med Biol. 2016;929:145-75.

31. Tai M, Stephanopoulos G. Engineering the push and pull of lipid biosynthesis in oleaginous yeast Yarrowia lipolytica for biofuel production. Metab Eng. 2013;15:1-9.

32. Hong SP, Seip J, Walters-Pollak D, Rupert R, Jackson R, Xue Z, et al. Engineering Yarrowia lipolytica to express secretory invertase with strong FBA1IN promoter. Yeast. 2012;29(2):59-72.

33. Dulermo R, Brunel F, Dulermo T, Ledesma-Amaro R, Vion J, Trassaert $M$, et al. Using a vector pool containing variable-strength promoters to optimize protein production in Yarrowia lipolytica. Microb Cell Fact. 2017;16(1):31

34. Huang $Y Y$, Jian XX, Lv YB, Nian KQ, Gao Q, Chen J, et al. Enhanced squalene biosynthesis in Yarrowia lipolytica based on metabolically engineered acetyl-CoA metabolism. J Biotechnol. 2018;281:106-14.

35. Marsafari M, Xu P. Debottlenecking mevalonate pathway for antimalaria drug precursor amorphadiene biosynthesis in Yarrowia lipolytica. Metab Eng Commun. 2020;10:e00121.

36. Madsen KM, Udatha GD, Semba S, Otero JM, Koetter P, Nielsen J, et al. Linking genotype and phenotype of Saccharomyces cerevisiae strains reveals metabolic engineering targets and leads to triterpene hyperproducers. PLoS ONE. 2011;6(3):e14763.

37. Jin CC, Zhang JL, Song H, Cao YX. Boosting the biosynthesis of betulinic acid and related triterpenoids in Yarrowia lipolytica via multimodular metabolic engineering. Microb Cell Fact. 2019;18(1):77.

38. Zhou YJ, Buijs NA, Zhu Z, Qin J, Siewers V, Nielsen J. Production of fatty acid-derived oleochemicals and biofuels by synthetic yeast cell factories. Nat Commun. 2016;7:11709.

39. Jin Z, Wong A, Foo JL, Ng J, Cao YX, Chang MW, et al. Engineering Saccharomyces cerevisiae to produce odd chain-length fatty alcohols. Biotechnol Bioeng. 2016;113(4):842-51.

40. Gao Q, Cao X, Huang YY, Yang JL, Chen J, Wei LJ, et al. Overproduction of fatty acid ethyl esters by the oleaginous yeast Yarrowia lipolytica through metabolic engineering and process optimization. ACS Synth Biol. 2018:7(5):1371-80.

41. Guo W, Sheng J, Zhao H, Feng X. Metabolic engineering of Saccharomyces cerevisiae to produce 1-hexadecanol from xylose. Microb Cell Fact. 2016;15:24.
42. Seip J, Jackson R, He H, Zhu Q, Hong SP. Snf1 is a regulator of lipid accumulation in Yarrowia lipolytica. Appl Environ Microbiol. 2013:79(23):7360-70.

43. Nasution O, Lee YM, Kim E, Lee Y, Kim W, Choi W. Overexpression of OLE1 enhances stress tolerance and constitutively activates the MAPK HOG pathway in Saccharomyces cerevisiae. Biotechnol Bioeng. 2017;114(3):620-31.

44. Park Y, Han GS, Mileykovskaya E, Garrett TA, Carman GM. Altered lipid synthesis by lack of yeast Pah1 phosphatidate phosphatase reduces chronological life span. J Biol Chem. 2015;290(42):25382-94.

45. Han GS, O'Hara L, Siniossoglou S, Carman GM. Characterization of the yeast DGK1-encoded CTP-dependent diacylglycerol kinase. J Biol Chem. 2008:283(29):20443-53.

46. Han GS, O'Hara L, Carman GM, Siniossoglou S. An unconventional diacylglycerol kinase that regulates phospholipid synthesis and nuclear membrane growth. J Biol Chem. 2008;283(29):20433-42.

47. Morano KA, Grant CM, Moye-Rowley WS. The response to heat shock and oxidative stress in Saccharomyces cerevisiae. Genetics. 2012;190(4):1157-95.

48. Xu P, Qiao K, Stephanopoulos G. Engineering oxidative stress defense pathways to build a robust lipid production platform in Yarrowia lipo/ytica. Biotechnol Bioeng. 2017;114(7):1521-30.

49. Serbian I, Csuk R. An improved scalable synthesis of $\alpha$ - and $\beta$-Amyrin. Molecules. 2018;23(7):1552

50. Luo Y, Li BZ, Liu D, Zhang L, Chen Y, Jia B, et al. Engineered biosynthesis of natural products in heterologous hosts. Chem Soc Rev. 2015:44(15):5265-90.

51. Köpke D, Schröder R, Fischer HM, Gershenzon J, Hilker M, Schmidt A. Does egg deposition by herbivorous pine sawflies affect transcription of sesquiterpene synthases in pine? Planta. 2008;228(3):427-38.

52. Santos IC, Chaumette A, Smuts J, Hildenbrand ZL, Schug KA. Analysis of bacteria stress responses to contaminants derived from shale energy extraction. Environ Sci Process Impacts. 2019;21(2):269-78.

53. Gao S, Tong Y, Wen Z, Zhu L, Ge M, Chen D, et al. Multiplex gene editing of the Yarrowia lipolytica genome using the CRISPR-Cas9 system. J Ind Microbiol Biotechnol. 2016;43(8):1085-93.

54. Zhang JL, Cao YX, Peng YZ, Jin CC, Bai QY, Zhang RS, et al. High production of fatty alcohols in Yarrowia lipolytica by coordination with glycolysis. Sci China Chem. 2019;62(8):1007-16.

\section{Publisher's Note}

Springer Nature remains neutral with regard to jurisdictional claims in published maps and institutional affiliations.
Ready to submit your research? Choose BMC and benefit from:

- fast, convenient online submission

- thorough peer review by experienced researchers in your field

- rapid publication on acceptance

- support for research data, including large and complex data types

- gold Open Access which fosters wider collaboration and increased citations

- maximum visibility for your research: over 100M website views per year

At BMC, research is always in progress.

Learn more biomedcentral.com/submissions 